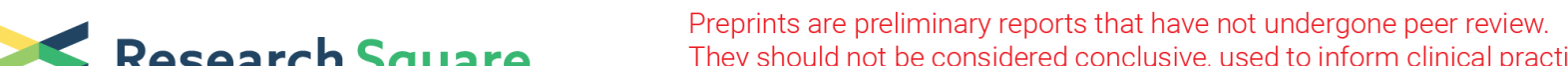 Research Square They should not be considered conclusive, used to inform clinical practice, or referenced by the media as validated information.
}

\section{Use of Idarucizumab in Ischemic Stroke: A National Experience in a Middle Income Country and a Concise Review.}

Julián Alejandro Rivillas ( $\square$ julian6692@gmail.com )

Fundación Valle del Lili: Fundacion Valle del Lili https://orcid.org/0000-0002-1231-9380

Arango Akemi

Fundación Valle del Lili: Fundacion Valle del Lili

Bayona Hernán

Santa Fe of Bogota Foundation: Fundacion Santa Fe de Bogota

Jaramillo Eugenia

Country Clinic: Clinica del Country

Amaya Pablo

Fundación Valle del Lili: Fundacion Valle del Lili

\section{Case Report}

Keywords: stroke, atrial fibrillation, thrombolysis, thrombectomy, Latin America, anticoagulation

Posted Date: June 4th, 2021

DOI: https://doi.org/10.21203/rs.3.rs-589277/v1

License: (c) (i) This work is licensed under a Creative Commons Attribution 4.0 International License. Read Full License 
1 USE OF IDARUCIZUMAB IN ISCHEMIC STROKE: A NATIONAL EXPERIENCE IN A MIDDLE INCOME

2 COUNTRY AND A CONCISE REVIEW.

3 Rivillas Julián ${ }^{(1,4)}$, Arango Akemi ${ }^{(5)}$, Bayona Hernán ${ }^{(2)}$, Jaramillo Eugenia ${ }^{(3)}$, Amaya Pablo ${ }^{(1,4)}$

4

5 1. Neurology Department, Fundación Valle del Lili, 2. Fundación Santa Fé de Bogotá, Stroke Center, 3.

6 Clínica del Country. 4. Universidad Icesi, Facultad de Ciencias de la Salud 5. Centro Investigaciones

$7 \quad$ Clínicas Fundación Valle del Lili.

8

9 Correspondent author: Pablo Amaya, MD. Stroke Program, Neurology Department. Fundación Valle 10 del Lili, Cra 98 No. 18-49, Cali 760032, Colombia. Phone number (57) (2) 3319090 ext 4022 . Icesi 11 University. Email: pablo.ricardo@fvl.org.co

\section{Abstract}

14 Background: Despite receiving anticoagulation for primary or secondary prevention for atrial fibrillation, new embolic events may occur. Current stroke guidelines contraindicate the use of thrombolysis if oral anticoagulants are used within 48 hours of symptom onset. Idarucizumab may be an alternative for patients receiving dabigatran with an acute stroke when alteplase is indicated. We present a series of four cases of patients who received idarucizumab in neurological emergencies in a middle-income country in Latin America.

Methods: Using the national pharmacologic surveillance data, we retrospectively collected the cases of idarucizumab used in acute stroke, including retinal thrombosis in Colombia between 2018 and 222020.

23 Results: Four male patients with atrial fibrillation received thrombolysis for acute stroke, and two of 24 them received mechanical thrombectomy. No major complications during hospitalization were present. One of the patients that received combined therapy presented with hematuria; the other 
26 patient that received thrombolysis presented with groin hematoma, but none required transfusion.

27 All had favorable mRS at discharge and 90-day follow-up.

28 Conclusion: The use of thrombolysis after reversal with idarucizumab in patients with ischemic stroke 29 is safe. Our patients presented favorable mRS at discharge and 90-day follow-up. The low number of 30 cases is related to the poor availability of idarucizumab. Only 11 hospitals in 5 cities have storage of 31 the medication. Stronger public policies are needed to guarantee optimal stroke treatment in patients 32 with atrial fibrillation receiving anticoagulation, including access to reversal and reperfusion therapies 33 to reduce further disability, especially in a middle-income country such as Colombia.

34

35 Keywords: stroke, atrial fibrillation, thrombolysis, thrombectomy, Latin America, anticoagulation 
Worldwide, atrial fibrillation (AF) accounts for $15 \%$ to $30 \%$ of ischemic strokes (1). Nonetheless, there is a dearth of data on the general use of anticoagulants, atrial fibrillation, and stroke in Latin America, where atrial fibrillation is estimated to account for $13 \%$ of the population over the age of 70 . (2). In 2014 , a cross-sectional study of administrative data revealed that 1.310 people received direct oral anticoagulant (DOACs) therapy in a database of 6.5 million people affiliated with the Colombian Health and Social Security System. Rivaroxaban was used in 53.1 percent of cases, dabigatran was used in 44.6 percent of cases, and apixaban was used in 2.3 percent of cases (3). Other local studies in a highlevel hospital between 2008 and 2013 revealed use of warfarin (71.2\%), enoxaparin (5\%), rivaroxaban (14.8\%), dabigatran (8.2\%), and apixaban (0.8\%) (4).

Historically, vitamin $\mathrm{K}$ antagonists (VKA) were the first line of anticoagulation treatment for patients with atrial fibrillation as a stroke prevention strategy due to their beneficial effect on mortality and disability (5). DOACs, on the other hand, have demonstrated non-inferior efficacy to VKA in patients with non-valvular atrial fibrillation (NVAF) (6). This is why the FDA approved rivaroxaban, apixaban, dabigatran, and edoxaban for the purpose of preventing stroke in patients with NVAF. Unlike VKA, DOACs have a broad therapeutic window, do not require frequent dose adjustment, and have few known interactions with food and other pharmacological groups. Nonetheless, DOACs lacked agents capable of rapidly, precisely, and safely reversing their effect. As a result, particular emphasis has been placed on developing specific agents capable of reversing DOAC's anticoagulant effect. As a result, andexanet alfa, idarucizumab, and ciraparantag have been evaluated for their potential use in reversing the effects of direct anticoagulants (7). Idarucizumab is a humanized monoclonal antibody

58 fragment that has a high affinity and specificity for dabigatran and is capable of rapidly reversing 59 anticoagulant activity (8). These drugs have been most frequently used in emergency situations for hemorrhage or urgent surgery. However, the pivotal trials excluded the possibility of using the drug in patients with ischemic stroke. It was quickly used in this clinical scenario prior to thrombolysis and 
thrombectomy. Concerns about its efficacy and safety in these patients were raised, but individual case reports and small case series quickly reported a possible use in this subgroup of patients. Additionally, some cases of reperfusion combined therapy (intravenous thrombolysis plus thrombectomy) following idarucizumab reversal have been reported with favorable preliminary results (9). We describe the use of idarucizumab prior to reperfusion procedures in four cases of ischemic stroke in Colombia where access to this medication is still limited. See figure 1.

\section{Cases presentation}

69 Between 2018 and 2019, four male patients aged 64 to 79 years presented to the emergency department of three institutions in Colombia, two in Bogotá and one in Cali, due to neurological deficits. Each patient had a previous modified Rankin scale (mRS) score of 0, a history of AF, and was receiving dabigatran anticoagulation. Two patients presented with severe National Institute of Health Stroke Scale (NIHSS) 21 and 22, while the remaining two presented with mild to moderate stroke (2 and 9). All patients received thrombolysis following reversion to idarucizumab. In $3 / 4$ of cases, a prolonged time from door to needle (> 60 minutes) was observed. Two patients required mechanical thrombectomy, which took 200 and 260 minutes from door to groin, respectively. In one patient, an asymptomatic hemorrhagic transformation was observed. Inpatient care lasted between six and fourteen days. Two patients developed mild complications as a result of hematuria and a groin hematoma that did not necessitate transfusion or intervention. All patients were discharged with an NIHSS score of 1 to 5 and an mRS score of 1 to 2 . The patients did not experience any new neurological events or mRS deterioration during the 90-day follow-up period. Table 1 contains detailed characteristics of clinical cases. 


\section{Discussion}

84 We describe the safe use of an anticoagulation reversal agent in neurological emergencies in Latin America. The disparity in access to health care in this part of the world creates significant barriers to stroke prevention, care in specialized centers, and access to safe reversal strategies when indicated. Anticoagulant therapy with VKA or DOACs reduces the risk of AF-related thromboembolic events. However, between $1 \%$ and $2 \%$ of patients with NVAF who are anticoagulated with DOAC have an ischemic stroke $(10,11)$. Nonetheless, patients who have been chronically anticoagulated with any agent have been excluded from intravenous thrombolysis and mechanical reperfusion trials. Thrombolysis was considered, however, if the prothrombin time (PT) was less than 1.5 during VKA therapy or if the last dose of DOAC was administered within the previous $12-24$ hours with a normal glomerular filtration rate (11). Other studies justified its use when the last dose was administered 12 hours prior to the event or when a Thrombin Time (TT) of 38 seconds and a PTTa of less than 37 seconds were obtained (12).

Because serum DOAC levels are not routinely determined in clinical practice, the need for specific

DOAC reversers was generated. Idarucizumab is a monoclonal antibody fragment that rapidly reverses the effects of dabigatran and has been shown to be effective and safe in patients requiring emergency surgery or bleeding $(12,13)$. Nevertheless, none of the REVERSE-AD cohort patients received thrombolysis or mechanical reperfusion therapy for stroke. Around 225 patients have been reported to have received thrombolysis prior to reversal with idarucizumab since 2016 , but only $35 \%$ of them received mechanical thrombectomy. Even fewer patients receive combined therapy (see table 2).

103 Thrombotic complications occurred up to 30 days after follow-up in the REVERSE-AD. Nonetheless,

104 the presentation rate of these complications was low in the reported cases, and no thrombotic 105 complications occurred during the three-month follow-up period following idarucizumab 106 administration. However, these events, particularly in patients with cardioembolic strokes, may be related to the prothrombotic risk associated with AF per se (11). 
The average NIHSS score at admission was ten points in the cases reported, with 90 percent of patients presenting with a moderate to severe stroke, two of them with non-severe hemorrhagic complications. One patient was admitted with an NIHSS score of 21, was discharged with an NIHSS score of 2, and was followed for three months. Hematuria was present in this patient, but there were no cystoscopic abnormalities. Another patient presented with an inguinal hematoma at the puncture site, which had no effect on functional outcome but resulted in an additional ten days in the hospital.

114 Table 2 compares clinical and demographic data of the reported cases with the series published so far as we know.

116 Due to a paucity of published information on anticoagulation and reversal agents in our country, we 117 conducted a survey of general practitioners, medical students, residents, and members of various 118 medical specialties to ascertain their knowledge of DOACS and its use in an emergency. 34.4 percent 119 of the 337 respondents were general practitioners, 35\% were specialists, 21.1 percent were residents, and 9.5 percent were medical students. Internal medicine physicians comprised 17.3 percent of specialists and residents, followed by neurologists at 13.9 percent, emergency medicine practitioners at 5.8 percent, intensive care unit physicians at 3.4 percent, cardiologists at 2.4 percent, anesthesiologists at 3.1 percent, and other internal medicine subspecialties at 2.4 percent. $7.8 \%$ were from other medical specialties. 56.7 percent worked in a private academic hospital, 19.3 percent in a public academic hospital, 19 percent in a private non-academic hospital, and $5 \%$ in a public, nonacademic hospital. In general, 99 percent of respondents were familiar with warfarin, 95.5 percent with rivaroxaban, 93.2 percent with apixaban, and 91.6 percent with dabigatran, but only 32.3 percent with edoxaban. Globally, 95.5 percent of people were aware of specific anticoagulant antagonists; 73.9 percent were aware that dabigatran has a specific antagonist, but only 72.6 percent were aware of the specific name. When asked about the antagonist name for dabigatran in a hemorrhagic situation, 75.2 percent correctly identified idarucizumab as the indicated treatment. Despite this, only

13223.6 percent of hospitals have idarucizumab on hand, 27.8 percent have VII factor, 44.4 percent have prothrombin complex, 60.4 percent have cryoprecipitate, and 34.9 percent are unaware of these 
drugs' availability. 24.3 percent of 337 patients had used Idarucizumab in an emergency situation, with

135 the most common indications being digestive bleeding, hemorrhagic stroke, trauma, or previous surgical intervention. The medication's limited availability may explain why idarucizumab is rarely used in Colombia. According to national pharmacologic surveillance data for Idarucizumab in Colombia, only 11 private institutions have access to this medication in the form of limited units of ampoules (Figure 1). Additionally, it requires a customized electronic formulation for public and private healthcare users, adding to the burden of obtaining the medication.

142 Finally, a significant question that arises when a patient is discharged is how to manage secondary

143 prevention to minimize the risk of new events. Numerous patients in the case series did not provide

144 information about post-stroke management in the presence of dabigatran. Nonetheless, the switch

145 to a direct factor Xa inhibitor is common, despite the lack of evidence from prospective studies. Thus,

146 in the presence of NVAF and a history of intracranial hemorrhage and a contraindication to

147 anticoagulation or recurrent stroke, percutaneous closure of the left atrium may be considered (12,

148 13).

149 Idarucizumab is still unavailable in a number of centers, illustrating the disparity in access to care services within a developing country's health system, such as Colombia. Nonetheless, it has become a viable option for anticoagulated patients with a thrombolysis indication when available. It has been performed safely and with a low complication rate in patients with moderate to severe NIHSS.

153 Nonetheless, additional public policies are required to ensure the availability of idarucizumab in 154 developing countries in order to reduce stroke-related disability. 
156 List of abrevation

157 AF: Atrial fibrillation

158 DOAC: direct oral anticoagulant

159 CRA: Central retinal artery

160 ICU: Intensive Care unit

161 MCA: Middle cerebral artery

162 mRS: modified rankin scale

163 N.A: not available

164 NIHSS: National Institute of Health Stroke Scale

165 NVAF: non-valvular atrial fibrillation

166 PTP: partial time of thromboplastine

167 TICl thrombolysis in cerebral infarction

168 VKA: vitamin K antagonist 
170 Ethics approval and consent to participate:

171 All patients included in this study were registered with the institutional stroke registry at Fundación

172 Valle del Lili, Fundación Santa Fé de Bogotá, and Clínica del Country. Protocols that have been

173 evaluated and approved previously by the Institutional Review Board (IRB).

\section{Consent for publication}

175 All patients consented for publishing their information.

\section{Availability of data and materials}

177 The datasets used and/or analyzed during the current study are available from the corresponding

178 author on reasonable request.

\section{Competing interests}

180 The authors declare that they have no competing interests.

$181 \quad$ Funding

182 No funds were used to perform this study.

\section{Authors' contributions}

184 JR: conceived and presented idea. Wrote first manuscript, made search strategy

185 AA: wrote first manuscript, developed and applied survey

$186 \mathrm{HB}$ : contributed clinical information on patients, reviewed manuscripts 
PA: conceived idea, followed up patients, revised final manuscript

189 Acknowledgements

190 Not applicable 


\section{References}

1. Wolf PA, Abbott RD KW. Atrial fibrillation: a major contributor to stroke in the elderly. The Framingham Study - PubMed [Internet]. Arch Intern Med. 1987 [cited 2020 Oct 28]. p. 147:1561-4. Available from: https://pubmed.ncbi.nlm.nih.gov/3632164/

2. Machado-Alba JE, Gaviria-Mendoza A, Machado-Duque ME, Tovar-Yepes C, Ruigómez A, García Rodríguez LA. Use of non-vitamin K antagonist oral anticoagulants in Colombia: A descriptive study using a national administrative healthcare database. Pharmacoepidemiol Drug Saf. 2020;1-9. https://doi.org/10.1002/pds.5124.

3. Machado-Alba Jorge E., García-Betancur Santiago, Villegas-Cardona Federico, MedinaMorales Diego Alejandro. Patrones de prescripción de los nuevos anticoagulantes orales y sus costos económicos en Colombia. Rev. Colomb. Cardiol. [Internet]. 2016 July [cited 2020 Nov 20] $\quad 23 \quad(4): \quad 277-285 . \quad$ Available from: http://www.scielo.org.co/scielo.php?script=sci_arttext\&pid=S012056332016000400007\&Ing=en. http://dx.doi.org/10.1016/i.rccar.2015.08.005.

4. Ligia P. Laverde, Sonia E. Gómez, Ana C. Montenegro, Alberto Lineros, Beatriz Wills, Andrés F. Buitrago. Experiencia de una clínica de anticoagulación. (2015). Revista Colombiana de Cardiología, Volume 22, Issue 5. Pages 224-230, ISSN 0120-5633. https://doi.org/10.1016/j.rccar.2015.04.008.

5. Singer DE, Albers GW, Dalen JE, Go AS, Halperin JL, Manning WJ. Antithrombotic therapy in atrial fibrillation: The Seventh ACCP Conference on Antithrombotic and Thrombolytic Therapy. In: Chest [Internet]. American College of Chest Physicians; 2004 [cited 2020 Oct 28]. p. 429S 456S. Available from: https://pubmed.ncbi.nlm.nih.gov/15383480/ 
218 6. García L, Pérez M, Amaya P. Fibrilación auricular en pacientes con ataque cerebrovascular: experiencia en un centro de referencia del suroccidente colombiano. Acta Neurológica Colomb. 2015 Dec 8;31(4):363-8.

221

7. Truman J.Milling, Charles V.PollackMA. A review of guidelines on anticoagulation reversal across different clinical scenarios - Is there a general consensus? American Journal of Emergency Medicine38(2020)1890-1903

225

8. Schiele F, Van Ryn J, Canada K, Newsome C, Sepulveda E, Park J, et al. A specific antidote for dabigatran: Functional and structural characterization. Blood [Internet]. 2013 May 2 [cited 2020 Oct 28];121(18):3554-62. Available from: https://pubmed.ncbi.nlm.nih.gov/23476049/

9. Tse DM, Young L, Ranta A, Barber PA. Intravenous alteplase and endovascular clot retrieval following reversal of dabigatran with idarucizumab. J Neurol Neurosurg Psychiatry [Internet]. 2018 May 1 [cited 2020 Oct 28];89(5):549-50. Available from: https://pubmed.ncbi.nIm.nih.gov/28986468/

10. Alberts MJ, Eikelboom JW, Hankey GJ. Antithrombotic therapy for stroke prevention in nonvalvular atrial fibrillation [Internet]. Vol. 11, The Lancet Neurology. Lancet Neurol; 2012 [cited 2020 Oct 28]. p. 1066-81. Available from: https://pubmed.ncbi.nlm.nih.gov/23153406/ Guidelines for the Early Management of Patients With Acute Ischemic Stroke: A Guideline for Healthcare Professionals From the American Heart Association/American Stroke Association. 
Stroke [Internet]. 2018 Mar 1 [cited 2020 Oct 28];49(3):e46-110. Available from: https://pubmed.ncbi.nIm.nih.gov/29367334/

12. Pikija S, Sztriha LK, Sebastian Mutzenbach J, Golaszewski SM, Sellner J. Idarucizumab in Dabigatran-Treated Patients with Acute Ischemic Stroke Receiving Alteplase: A Systematic Review of the Available Evidence [Internet]. Vol. 31, CNS Drugs. Springer International Publishing; 2017 [cited 2020 Oct 28] p. 747-57. Available from: https://pubmed.ncbi.nlm.nih.gov/28808918/

250

13. Pollack C V., Reilly PA, van Ryn J, Eikelboom JW, Glund S, Bernstein RA, et al. Idarucizumab for Dabigatran Reversal — Full Cohort Analysis. N Engl J Med [Internet]. 2017 Aug 3 [cited 2020 Oct 28];377(5):431-41. Available from: https://pubmed.ncbi.nIm.nih.gov/28693366/ - A national case collection. Int J Stroke [Internet]. 2017 [cited 2020 Oct 28];12(4):383-91. Available from: https://pubmed.ncbi.nlm.nih.gov/28494694/

15. Ohya Y, Makihara N, Wakisaka K, Morita T, Ago T, Kitazono T, et al. Thrombolytic Therapy in Severe Cardioembolic Stroke After Reversal of Dabigatran with Idarucizumab: Case Report and Literature Review. J Stroke Cerebrovasc Dis. 2018 Jul 1;27(7):e128-31. Matute C, Vera R, Pérez-Torre P, Zamorano JL. Oral anticoagulation and left atrial appendage closure: a new strategy for recurrent cardioembolic stroke. Eur J Neurol. 2019 May;26(5):816820. doi: 10.1111/ene.13894. Epub 2019 Jan 28. PMID: 30586229. 
17. Cruz-González I, González-Ferreiro R, Freixa X, Gafoor S, Shakir S, Omran H, Berti S, et al. Left atrial appendage occlusion for stroke despite oral anticoagulation (resistant stroke). Results from the Amplatzer Cardiac Plug registry. Rev Esp Cardiol (Engl Ed). 2020 Jan;73(1):28-34. English, Spanish. doi: 10.1016/j.rec.2019.02.013. Epub 2019 Apr 27. PMID: 31036510. 
273 Tables and figures.

274 Table 1. Patients with ischaemic stroke treated with idarucizumab: characteristics and clinical 275 outcomes

\begin{tabular}{|c|c|c|c|c|}
\hline & Patient 1 & Patient 2 & Patient 3 & Patient 4 \\
\hline Year & 2018 & 2019 & 2019 & 2018 \\
\hline Gender & Male & Male & Male & Male \\
\hline Age & 67 & 64 & 69 & 79 \\
\hline \multirow[t]{4}{*}{ Comorbidities } & Parkinson & Previous & Hypertension & Hypertension \\
\hline & disease & stroke & Bradi-tachy & \\
\hline & Heart & Dyslipidemia & syndrome & \\
\hline & failure & Smolor & & \\
\hline
\end{tabular}

Atrial fibrillation

Type Paroxysmal Paroxysmal Permanent Paroxysmal

CHA2DS2-VASC

4

5

5

5

\section{Dabigatran}

Dose (mg/day)

300

300

300

300 


\section{Stroke}

Previous mRS

Occluded artery

Last known well (min)

Arrival NIHSS

PTT (sec)
0

Left MCA

120

21

39
0

CRA

130

2

9

42
0

Right MCA

Left MCA

120

22

38

\section{Reperfusion therapy}

IV thrombolysis

$\begin{array}{ccccc}\text { Mechanical } & \text { Yes } & \text { Yes } & \text { Yes } & \text { Yes } \\ \text { thrombectomy } & \text { Yes } & \text { No } & \text { No } & 220 \\ \text { Door-to-needle (min) } & 59 & 130 & 75 & 260 \\ \text { Door-to-groin (min) } & 200 & - & - & 3 \\ \text { TICl scale } & 3 & - & - & \text { HI } 1 \\ \text { Hemorrhagic } & & \text { No } & & \text { No } \\ \text { transformation } & \text { No } & & & \end{array}$


Inpatient care

Global stay

ICU stay

30-day systemic

thrombosis

30-day systemic

hemorrhage

Hematuria

No

Hematoma*

No

2

2
2

2
6

2

10

2 $\begin{array}{lll}\text { No No No } & \text { No }\end{array}$

$\begin{array}{lll}\text { No No No } & \text { No }\end{array}$
Discharge NIHSS

1

Discharge mRS

Follow up

90-day NIHSS

90-day mRS

Secondary prevention

N.A

Dabigatran

277 Intensive Care Unit, NIHSS: National Institute of Health Stoke Scale, mRS: Modified Rankin Scale,

278 NA: not available, CRAO= central retinal artery occlusion, *Groin hematoma. 
Author

Šaňák et

Barber et Pretnar

Kermer Synthesis of

al.

al. et al.

et al.

Isolated

Reported

Cases

n

13

51

19

80

62

Country Chech New Zeland Slovenia Germany Multiple

Republic

Age $(y)$, mean \pm SD

$70.0 \pm 9$

$73.3(12.2)$

75 (11.2)

75.9

$73(9.7)$

(10.7)

Males, n (\%)

7 (53)

$37(72.5)$

$10(53)$

$51(67.3)$

$36(58)$

Arterial Hypertension, $\mathbf{n}(\%) \quad 12(92.3) \quad-\quad-14(74) \quad-\quad 41(66)$

Diabetes mellitus, $\mathbf{n}(\%)$

$4(30.1)$

$1(5)$

13(20) 
Ischaemic Heart Disease, $\mathbf{n} \quad 6(46.2) \quad-\quad-\quad$ - $\quad 7(11)$

(\%)

\begin{tabular}{|c|c|}
\hline trial Fibrillation, n (\%) & $11(84.6)$ \\
\hline
\end{tabular}

Hyperlipidemia, n (\%) $\quad 6(46.2)$

Previous Stroke, $\mathbf{n}(\%) \quad-\quad 2(11) \quad-\quad 14(22)$

CHA2DS2-VASc, mean \pm SD $\quad-\quad-\quad 3(4) \quad-\quad 5(1,2)$

Admission NIHSS, median $\quad 7(3-23) \quad 8(5-17) \quad 9(18) \quad 9.7(5.1) \quad 10(7,5)$

(range)

Dabigatran dosage

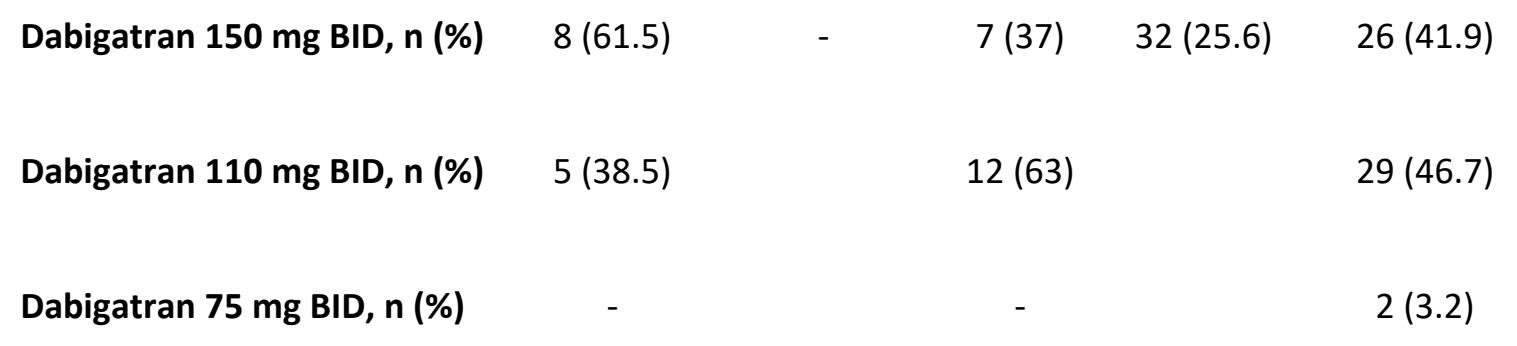


unknown, n (\%)

Proximal Vessel Occlusion, $\mathbf{n}$

(\%)

Admission aPTT (s), mean \pm

$38.1 \pm$

42.7

$37.7(20.8)$

SD

27.8

(15.1)

aPTT above normal, $\mathrm{n}(\%)$

$15(78)$

Admission TT (s), mean \pm SD

104.5

$112(53)$

(63.9)

The interval between the last $\quad 291 \pm 235$

$300 \pm 343$

intake of DB and

stroke onset (min), mean \pm

SD 
rTPA full dose

rTPA diminished dose

Tenecteplase

Not specified

Door-to-needle time, min; $\mathbf{n}$

(\%)

Mechanical Thrombectomy, $\mathrm{n}$

$1(8)$

8 (16.7)

$12(63)$

6

$8(12.8)$

(\%)

Door-to-groin time (T1, T2,

T3) $\min$

90-d good clinical outcome $\quad 10(76.9) \quad-\quad 16(84)$

(mRS score 0-2),

n (\%)

Dabigatran restarted, n (\%) $10(70)$

$22(35.4)$

Apixaban started, $\mathrm{n}(\%)$

$3(30)$

$5(8)$ 
(\%)

(\%)

ICH on control CT or MRI, $\mathbf{n} \quad 2(15.4) \quad-\quad 4(21) \quad-\quad 5$ (8)

(\%)

SICH on control CT or MRI

$1(7.7)$

2 (3.9)

$1(5)$

$2(3.2)$

after 24 h, n (\%)

Other bleeding complications

None

None

Mortality, n (\%)

$3(23.1)$

$3(5.9)$

$2(10)$

$2(3.2)$ 
283 Figure 1. Distribution map of cities and centers with availability of Idarucizumab in Colombia

284 according to the Idarucizumab surveillance program in Colombia. The number indicates the 285 total center with availability of the drug.

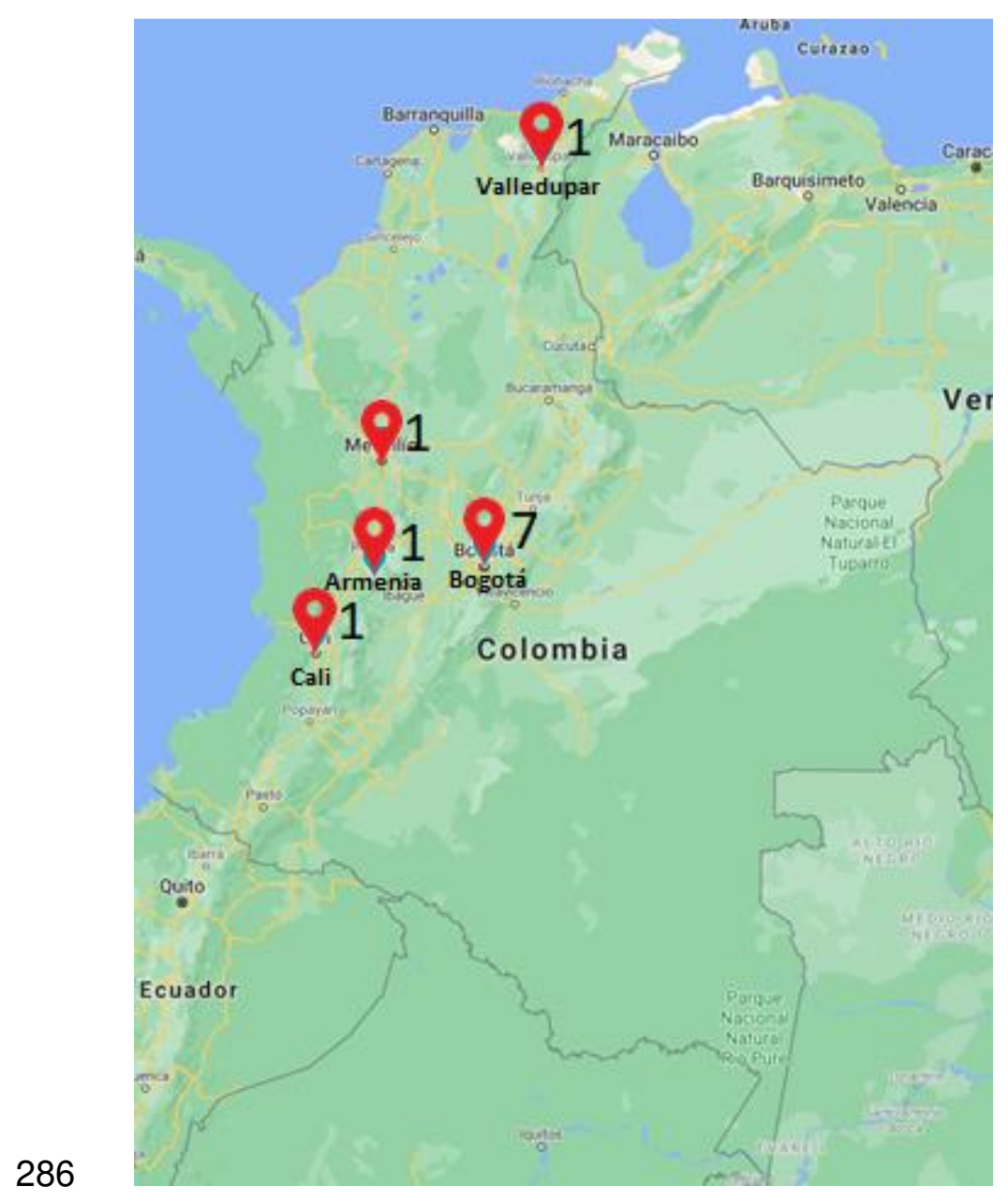

